\title{
POESIA, IMAGENS E DISCURSOS: GENTES CANTADAS, MOSTRADAS E FALADAS (POSSIBILIDADES DE LER GENTES E LUGARES EM MARGENS E FRONTEIRAS DA GEOGRAFIA)
}

\author{
Jones Dari Göetert \\ Universidade Federal da Grande Dourados - Brasil
}

\section{RESUMO}

A partir de incursões sobre representações literárias e imagéticas, com o presente artigo, procura-se refletir sobre gentes, fronteiras e lugares da Amazônia acreana, destacando sinuosos caminhos de rios, florestas e cidades, no tecer de sentidos a uma espécie de "tradução geográfica" que, assumindo a liberdade do texto literário, possa penetrar e ocupar lugares em frestas menos rígidas que as possibilitadas pela ciência, especialmente, tendo em vista que sua narrativa pode ser mais próxima das comunidades de leitores. A construção/invenção identitária de uma certa acreanidade é perscrutada na interpretação dos textos e imagens, pontuando uma análise também preocupada com as relações de poder aí instituídas, isto é, uma análise que se imiscui por entre as contradições, ambiguidades, contrastes, tensões e conflitos que se materializam na produção do espaço, na narrativa desse mesmo espaço e suas formas de idealização.

PALAVRAS-CHAVE: Amazônia acreana. Geografia. Literatura. Poesia. Fronteiras.

"Por que ensina o professor a geografia da morte?"

(Livro das perguntas, Pablo Neruda)

Galáxias percorrem

Meu infinito. Buracos negros invadem a calma do meu quintal.

$\mathrm{O}$ universo repousa na rede atada em meu jardim.

(Espacial, Francis Mary)

\section{Introdução}

Afirmar que "tudo é geografia" pode ser um jeito fácil de afirmar que o espaço está em todo o lugar. O problema é que em "tudo é geo- 
grafia" perdemos a especificidade, a particularidade e, vice-versamente, a diversidade, a multiplicidade. Por isso, talvez seja melhor dizer que em tudo há indícios para se ver, olhar e fazer geografia.

É possível perceber traços para um pensar e fazer geografia na literatura em prosa e na literatura em verso, como na fotografia, no cinema, na música, em jornais e em revistas, dentre outras possibilidades.

Por exemplo: onde estaria alguém - talvez uma "Bruxinha" que escreve "Galáxias percorrem meu infinito"? Em alguma galáxia ou no infinito? Para logo em seguida insistir: "Buracos negros invadem a calma do meu quintal"! Haveria relação entre buracos negros e quintal? Onde? E termina assim: "O universo repousa na rede atada em meu jardim". Universo e jardim. Uma rede. Apenas, uma rede.

Espaço? Espaço sideral ou espaço de uma rede de dormir? Espaço "galáxico" ou espaço do quintal?... Que espaço? Embriaguez? Alucinação? Imaginação? Sim, a imagem tornada palavras é reveladora de um êxtase literário. Um êxtase poético. É possível ver geografia no fantástico? Uma geografia que migra de uma galáxia qualquer para uma casa também qualquer. Queremos, aqui, que seja uma casa próxima do rio Acre ou do Purus, do Juruá... Que seja, então, “A casa do rio":

\footnotetext{
$\mathrm{Na}$ varanda da casa a menina ria, feliz com as histórias que o tempo lhe contava.

Nos anos de enchentes, as mangueiras floradas de moleques, se afogavam.
}

1 Francis Mary Alves de Lima, autora do poema em epígrafe (em Pré-históricas e outros livros. Rio Branco: Fundação Cultural Elias Mansour, 2004, p. 68). 
Ao lado, na casa das putas, o pandeiro espantando a solidão e a música do sax se enfiando

por entre pernas e sexos, tecia casos de devassidão.

No pôr do sol ela olhava o rio tornando mais finos os bodós que mastigava enquanto sonhava. ${ }^{2}$

Quantos lugares. Quanta gente. Quantos bichos. Que geografia!

\section{Versos e prosas}

Podemos dizer que há jeitos muito variados de conhecer os lugares e suas gentes. Falamos acima que um delas é através da literatura, de vários e vários livros escritos em prosa e verso sobre lugares vividos ou imaginados. Mas, mesmo na imaginação, na poesia, ${ }^{3}$ parece haver sempre pedacinhos de lugares vividos, porque a escritora ou o escritor escreve de um lugar, e parece improvável, ao escrever, deixá -lo completamente.

Os estudos que procuram envolver geografia e literatura, segundo Solange Terezinha de Lima,

buscam desvendar, no contexto de algumas obras de literatura, a percepção de uma cosmovisão da paisagem geográfica, que tem implicações diretas ou indiretas nas atitudes e condutas dos escritores e personagens, e, por extensão, dos leitores, diante dos seus espaços vividos. [...] a percepção geográfica relacionada à paisagem literária, construída com o lastro do real ou não, nos revela novas e amplas trilhas de ação e realização no desenvolvimento da teoria e da pesquisa geográfica (LIMA, 1999, p. 171).

2 Idem, p. 34.

3 Sobre território, poesia e identidade ver Rogério Haesbaert, Territórios alternativos, 2002. 
Uma geografia livre, com a literatura, pode fazer com que penetramos nos lugares por frestas menos rígidas que a ciência, na medida em que sua narrativa pode ser mais próxima das leitoras e dos leitores. Contudo, é sempre necessário pegar um livro, um jornal ou uma revista, abrir e mergulhar nas letras que formam palavras, que formam frases, que formam parágrafos, que formam imagens, que formam versos e que (in)formam lugares e gentes.

Em versos sobre o Acre e suas gentes, desde o início do século $\mathrm{XX}$, mulheres e homens foram ladrilhando lugares e pessoas. ${ }^{4}$ Cada verso foi, ao longo do tempo, ajudando a construir a idéia e a materialidade do Acre, de acreanas e acreanos. Portanto, o Acre e suas gentes fazem parte de um movimento de construção - ação, enfim - em quem as mulheres e os homens, em rios, igarapés, vilas, cidades, campos e floresta foram incorporando e vivendo um jeito que traziam de outros lugares (como do Nordeste) e tempos (como dos povos indígenas), misturando-o a novos jeitos. O jeito acreano (ou os jeitos acreanos...). Um jeito, por isso, que é múltiplo e diverso, pobre e rico, desigual e contraditório (é, sem dúvida, muito diferente ser acreano pobre ou acreana rica; ser ribeirinha ou moradora do Bairro do Bosque, em Rio Branco; ser "colonheiro", em Feijó ou criança Jaminawa, em Assis Brasil...)

No Acre, incursionando sobre a literatura em verso, uma das primeiras composições, ainda em 1903, ano do Tratado de Petrópolis, foi o texto que virou também o hino acreano, ${ }^{5}$ composto por Francisco Mangabeira, no Seringal Capatará.

O novo território, então brasileiro, "precisava" de um símbolo que identificasse, pela letra e música, as suas gentes com o lugar... O 4 Sobre a Literatura acreana ver o importante trabalho de Laélia Rodrigues da Silva, Acre; prosa \& poesia (1900-1990), 1998.

5 Os trechos do hino acreano, como também os versos de Luiz Gonzaga Salles e Juvenal Antunes, fazem parte de uma antologia no final do livro de Laélia Rodrigues da Silva, 1998. 
hino fala do sol, da mata, dos rios, da guerra, de sangue e luta, de terra, de esposas e mães que esperam, de estrangeiros... Vejamos alguns versos:

As esposas e mães carinhosas / A esperar-nos nos lares fiéis / Atapetam a porta de rosas / E cantando entretecem lauréis. / Mas se o audaz estrangeiro algum dia / Nossos brios de novo ofender, / Lutaremos com a mesma energia / Sem recuar, sem cair, sem temer. / E ergueremos, então, destas zonas, / Um tal canto vibrante e viril / Que será como a voz do Amazonas / Ecoando por todo o Brasil...

Os versos evocam aspectos bastante fortes sobre o território e a relação - simbólica e material, principalmente a primeira - que as gentes foram construindo. Terra, sangue, guerra e inimigo (os "estrangeiros"), têm um forte apelo na construção de uma identidade. E sempre é bom lembrar que, em 1903, muitos homens no Acre - com "As esposas e mães carinhosas/A esperar-nos nos lares fiéis" - recém haviam participado dos conflitos armados com a Bolívia, possibilitando tornar brasileiro o território.

Ao estabelecer o outro inimigo - "estrangeiro" - também se produziu e se fortaleceu o eu, a idéia de ser acreano ou ser acreana. Esse ser pertence a um território, a um lugar, que, no próprio hino, já apontava para um pertencimento maior: a Amazônia, o Brasil. Contudo, não deixa de expressar sua singularidade que faria do território e de suas gentes, daí para adiante, a construção da singularidade: o que fora definido e difundido, principalmente como construção oficial de um governo ("governo da floresta", que assumiu em 1998 e foi reeleito em 2002 para o governo estadual), como acreanidade.

A construção da identidade acreana, no entanto, foi e é permeada por contradições, ambiguidades, contrastes, tensões e conflitos, que se materializam no espaço. Por relações de poder. Ou seja, nem todas e todos são acreanas e acreanos da mesma forma, do mesmo jeito: há quem tenha muito e há quem tenha pouco... Geralmente, contudo, a 
identidade tende a homogeneizar as gentes ao buscar "dizer" que os interesses dos grupos dominantes são os interesses de todas e todos.

Apontando já contradições, Luiz Gonzaga Salles, em 1922, em Sena Madureira, no soneto "Deserto verde", falava de um "Eldorado" que perdia seu brilho e estampava - pela crise do baixo preço da borracha, principalmente pela perda da hegemonia produtiva para a Malásia a partir de 1912-1913 - o "Tugúrio de miséria, fome e peste!" (tugúrio = cabana, refúgio, abrigo... Lugar?) e "Que pouco os habitantes perde". Denunciava, em versos, a pobreza e a migração de gentes para longe e chegando à conclusão de que "O Acre escuso, tão querido outrora/Co'a sempre verde exuberante flora/Vai-se tornando num deserto verde".

Em aproximação, também Juvenal Antunes, em Rio Branco (1929), no soneto "O Acre", versou sobre uma "Terra gigântea e nova, opulenta e tenaz,/Que a miséria e a ambição povoaram de repente". A opulência, pouco a pouco, foi dando lugar à constatação da miséria e dos contrastes. Uma riqueza do passado que também deve ser questionada, pois não parece haver dúvidas que o resultado do trabalho, de milhares de famílias de seringueiros, era concentrado e gasto por muito poucos, os "coronéis", "patrões" ou "seringalistas". E não por quem, efetivamente, produzia: a produção era socializada, mas era privada a sua apropriação.

Juvenal Antunes, no mesmo soneto, ressaltou que "Aqui corria outr'ora, em imensas caudais, $/ \mathrm{O}$ rio do dinheiro, em tumultuosa enchente;/E era belo de ver como este heróica gente/Disputava o bastão de quem gastava mais"... Só que no "rio de dinheiro" nem todas e todos nadavam!

A concentração de riqueza e de poder, no território acreano e em cada um de seus lugares, não impediu a reprodução e a afirmação de 
uma identidade acreana (diversa, novamente ressaltamos), como expressão de uma certa unidade e comunidade de origem e de destino... A formação da identidade - portanto, da própria territorialidade - deve também ser lida na sua positividade como comunidade de sentido e como sentimento de pertencimento - aliás, um dos aspectos que possibilitou a resistência e luta, nos anos 1970 e 1980, de seringueiros, suas esposas e crianças, contra uma territorialidade seringalista, pecuarista e latifundiária, com gentes como Wilson Pinheiro e Chico Mendes. ${ }^{6}$

Nessas geografias dos versos, é possível trazer à tona elementos do espaço amazônico em geral, e do acreano - e de seus lugares - em particular. O que se quer ressaltar, sobretudo, é que não são os versos a geografia, mas neles e através deles pode se ler o espaço. Fazer geografia. Ver os seus lugares. Pensar e compreender as relações no espaço. E isso não significa "tirar leite de pedra"!

Já ouvimos, no Acre, que, pela ausência de rochas pelo menos superficiais, o número de olarias é significativo... E vira espaço, e vira poesia... Sobre o barro, as olarias e a sinuca - há espaço capaz de juntar os três? -, o escritor Clodomir Monteiro produziu um poema que possibilita pensar gentes e lugares do "barro":
estou
nas paredes desta casa
sangue dos pequenos
oleiros
nos discursos deste texto
tecido das pequenas
mãos
nos desenhos desta rua
caminho dos pequenos
pés
no ventre deste poema

6 Ver Carlos Walter Porto Gonçalves, Geografando nos varadouros do mundo: da territorialidade seringalista (o serignal) à territorialidade seringueira (a Reserva Extrativista), 2003. 
poesia/fome das pequenas

bocas

empilhadas

nas olarias tabernas e sinucas (MONTEIRO, 2003, p. 16).

O texto parece distribuído como o são os tijolos de uma construção reta. Versos tortos. Espaço vazio preenchido pela metade. Nos oleiros as mãos, os pés e as bocas parecem ansiar tabernas e sinucas, não olarias. Dos oleiros - de suas mãos e pés... - vão sendo produzidos tijolos para as "paredes desta casa" e para os "desenhos desta rua". Nas paredes e ruas vemos apenas tijolos; não vemos as mãos e os pés que fizeram tanto as paredes e ruas como os tijolos. Mãos, pés e bocas, longe das casas e das ruas, estão nas tabernas e nas sinucas. ${ }^{7}$

Também o "boteco", esse lugar amado e amaldiçoado simultaneamente, e em perspectiva diferente em relação a Clodomir Monteiro, foi lugar do poeta Armando Pompermaier em "Venenos, gases e esparadrapos (Etilicoterapia coletiva)".

Vou encontrar uns amigos

vamos destruir nossas esperanças

pra evitarmos decepção

Vamos embriagar toda mágoa

que existe em nosso coração

beber até cair no chão [...]

Não aguento mais viver nas mesmas paredes,

talvez trocar de ambiente [...]

Estamos no vômito

Isso é o que podemos esperar

que haja de melhor em nossas vidas:

o vômito

Confraternizemos vômitos!

Espero que o seu seja bem grande,

espere o mesmo de mim, somos amigos,

$7 \quad$ Na década de setenta já era salientado o importante número de tabernas na periferia de Rio Branco. Ver Luiz Antônio Pinto de Oliveira, O sertanejo, o brabo e o posseiro: a periferia de Rio Branco e os cem anos de andança da população acreana, 1982. 
não terei nojo:

verei apenas seu alívio

É o melhor que podemos esperar

de nossa miserável vida (POMPERMAIER, 2003).

São, acima, as mesmas paredes de antes? O mesmo boteco? Vidas, todas miseráveis? Lugares escondidos? Que gentes são essas? Os versos não descansam nunca e nem nos deixam descansar em paz, principalmente quando sacudidos por um espaço carregado de tensões - individuais e coletivas - que se mostram em palavras duras, "concretadas" que, se soltas, talvez nos deixassem seguir adiante, ou mesmo nem notaríamos nem gentes e nem os seus lugares: vômito, nojo... Este é o "risco" em pensar versos, gentes e lugares: nem sempre achamos "parques da maternidade" ou "gameleiras"... Às vezes, nem olarias, nem tijolos e nem comida para se vomitar depois (GOETTERT, 2004 e 2005).

Também a literatura em prosa apresenta enormes possibilidades de pensar elementos de uma geografia das gentes do Acre. Em "Rios e barrancos do Acre", de Mário Maia, escrito no início dos anos 1960, é possível ter um leitura do "homem" da floresta, como a apresentada a seguir:

O homem enclausurado nas lianas individualizantes da densa floresta, em tedioso e absorvente separatismo social, sem assistência de espécie alguma, de repente vê-se assaltado por uma força incognocível que lhe excita o desejo de dirigir-se a alguém para ver e falarlhe, de um modo tão forte quanto o impulso sexual. Então o animal gregário, despertado agora nos atavismos de sua raça, larga tudo e põem-se a andar, andar, andar, varadouro afora até encontrar-se com um outro ser que emita e articule sons iguais aos sons que ele articula e emite. Não raro é de tal forma grande a sua satisfação que a mesma quase se transforma em êxtase: - não se importa sequer de falar. Compraz-se em ouvir a voz de seu semelhante como a saborear uma fruta (MAIA, 1978, p. 38).

Um "homem enclausurado": preso... A prisão: a floresta, "densa 
floresta"... Longe de uma pretensa sociedade e "sem assistência de espécie alguma"... O autor, ao anunciar o isolamento e as dificuldades de comunicação, também denuncia o precário papel do Estado... "Sem assistência". Este "homem" solitário (não há referência à mulher) clama em pelo menos ouvir a voz de alguém "que emita e articule sons iguais aos sons que ele articula e emite". Mário Maia traçou um perfil desse "homem", "animal gregário", que anda, anda e anda: perfilar é também produzir, construir, inventar, imaginar e viver espaço, viver espaços.

No entanto, o "andar", acima, não fazia do "animal gregário" um migrante. Mas em "Terra caída", de José Potyguara, publicado pela primeira vez em 1961, o seringueiro Chico Bento lembra do lugar deixado - o Ceará - e se re-faz no lugar chegado: ${ }^{8}$ a Amazônia...

$\mathrm{Na}$ faina diária do corte, Chico Bento percorre duas vezes a mesma estrada sinuosa e sombria. Caminhando sozinho, vai recordando fatos da sua vida: a infância feliz, na companhia dos nove irmãos, os sonhos da mocidade, a morte do pai, seu casamento, na capelinha da vila, na Serra da Meruoca, o nascimento das duas filhas... De repente, o flagelo da seca, estorricando a terra, matando tudo de sede e de fome! O jeito era emigrar. Apareceu por lá uma paroara contratando homens para os seringais. Bem vestido e muito conversador, contava grandes vantagens da terra da borracha. Com a fome e as necessidades aumentando cada dia, ninguém era idiota para continuar ali, esperando a morte. Preferível ir embora, aventurar por aí, ao Deus-dará, contanto que escapasse! (POTYGUARA, 1998, p. 12).

Primeiro, José Potyguara, no excerto, narrando sobre Chico Bento, fala da "faina diária", o corte da seringa. Uma "estrada sinuosa e sombria". O espaço visto como medo. Na caminhada, também sozinho, recorda fatos e lugares. A Serra da Meruoca. Lembra da seca, da sede e da fome no Nordeste. "O jeito era migrar". Para a "terra da borracha"...

8 Sobre lugar deixado e lugar chegado ver Jones Dari Goettert, O espaço e o vento: olhares da migração gaúcha para Mato Grosso de quem partiu e de quem ficou, 2004. 
O autor possibilita pensar dois lugares. Dois espaços. Do Nordeste e da Amazônia. A falta de água em um e a abundância dela em outro. Possibilita ainda pensar uma certa geografia das migrações para a Amazônia, prenhe tanto de questões de ordem econômica como também de questões de ordem política, cultural, subjetiva, emotiva, afetiva. O material e o simbólico participando da constituição do espaço e de seus lugares (GOETTERT, 2003).

Lugares feitos e refeitos como também relatado por dona Francisquinha na comunidade ribeirinha Pucalpa III, entre Porto Walter e Rodrigues Alves, à margem esquerda do Juruá. Disse ela que quando chegaram ali - com a família, há mais de sessenta anos - o pai começou a erguer um tapirizinho enquanto a mãe ajuntava lenha para uma fogueira, porque no dia seguinte era dia de Santo Antônio. A mãe levava, para os "confins" da Amazônia Sul-Ocidental, pedaços da religiosidade popular nordestina. O lugar que se fazia junto à família de dona Francisquinha era também constituído por tempos diferentes: o passado e o presente... e na fé, na esperança, na oração, o futuro... Pois, ali, no passado e no presente, o futuro já mostrava sua "cara", se "insinuava" e "acariciava" os gravetos, as lenhas secas das árvores caídas sem força, de mortes sem serras nem motosserras.

Miguel Jeronymo Ferrante escreveu sobre Toinho, que também lembrava do pai:

O pai era um bom seringueiro. Trabalhava três estradas da "colocação", alternadamente, na época do fabrico. Iniciava o corte às duas horas da madrugada e o fechava cerca de meio-dia. Na embocadura do varadouro, comia a minguada refeição que trouxera da barraca, uma farofa de banha misturada com um pouco de feijão ou arroz frio, e tornava à estrada para a colheita. Ia derramando leite das tigelinhas no balde e, quando este enchia, despejava o conteúdo num saco encauchado, cuja boca amarrava com uma fita de balata. Já quase noite, voltava à barraca e ia direto ao defumador, para não correr o risco de ver, com qualquer demora, o látex transformado em sernambi. A borracha colhida, entretanto, nunca dava para pagar o débito do Barracão, para comprar nada além da banha, do tabaco, 
do feijão, do arroz, do querosene, do sabão, do açúcar e do sal. Uns metros de riscado. Uns cartuchos. Nas safras boas, uma manta de pirarucu seco, uns quilos de jabá ou uma lata de carne-bife (FERRANTE, 2003, p. 29).

Diferente dos excertos de Mário Maia e de José Potyguara, nesse Miguel Jeronymo Ferrante descreve o dia de um seringueiro, seus lugares e a contradição no sistema de aviamento: quem trabalha, trabalha; e o patrão se apropria da produção. Por outro lado, o autor vai dando pistas importantes para a compreensão do território seringal e em particular da colocação, dos caminhos, do trabalho e de seus lugares. Lugares que vão se fazendo na relação com o corte da seringa, seu transporte, a defumação, a comida... Território também de tensão entre as gentes da colocação e do barracão: no final das contas, as contas rezam pelo crédito do patrão e pelo débito de quem trabalha.

Mais recentemente, em 2002, Florentina Esteves, em "Enredos da memória", no texto "Ciranda", escreveu de um "tempo sem data", de um tempo que se imbricou em outro possibilitando, pela leitura, acessar espaços e lugares distintos. A autora escreveu em "Ciranda" principalmente sobre mulheres: florista, bordadeiras, doceiras, costureiras, professoras, pianistas... Do meio para o fim da ciranda, escreveu:

Brincavam de gente grande as crianças. As mamães amamentavam, taberneiros tabernavam, cozinheiras cozinhavam, doceiras faziam doces, costureiras costuravam e bordadeiras bordavam o enxoval do bebê que esperavam.

E por entre catraias de toldo azul, sem pressa passava o dia. Naquele tempo sem data.

Até que um dia... no rio puseram ponte, na ponte passando carros, nos carros passando gente. Gente apressada correndo, Gente que pára e espia o rio, revendo infância vadia nos passeios de catraia ao banzeiro de chatinha. E outras gentes, vindas de outras paragens e de outros horizontes, que não sabem de "seu" Neco catraieiro, do tacacá da Donana, dos domingos com retreta, ser comadre de fogueira, dançar valsa na Festa das Flores da Tantamen. Que não sabem do apito da Usina na hora que a luz apagava e nem do porto enfeitado 
de embarcações - luzes tremeluzindo entre o baço da garoa. Gente que não sabe das dimensões do percurso entre o crepúsculo da Volta da Gameleira e onde o olhar se perdia lá na curva da "Judia". E da rua da África que um dia, desviado de seus domados caminhos, o rio invadiu e sepultou sob balseiros.

Não saberá... (ESTEVES, 2002, p. 110).

A autora vai permeando o mesmo espaço em tempos diferentes. Lugares diferentes. Diferentes porque tanto as mudanças mexeram nas coisas como as pessoas já não são as mesmas. Tanto as gentes que brincavam, as "mamães [que] amamentavam, taberneiros [que] tabernavam, cozinheiras [que] cozinhavam, doceiras [que] faziam doces, costureiras [que] costuravam e bordadeiras [que] bordavam o enxoval do bebê que esperavam", como as gentes de fora.

O que a autora diz, para uma leitura geográfica? Várias, várias coisas. Mas talvez a principal seja a de que os lugares são a interação entre tempos e que as gentes, nesses tempos, apreendem diferentemente o mesmo lugar, a mesma ponte, a mesma rua e mesmo a mesma curva do rio. É que o mesmo deve ser relativizado, porque é visto, percebido, sentido, apreendido, inventado, imaginado, vivido e representado em perspectivas diferentes. Não há, por isso, maior legitimidade em um sobre outros casos. Da mesma forma, a autora é extremamente provocadora ao estimular nosso olhar geográfico tanto para as mudanças materiais dos lugares como nas múltiplas apreensões simbólicas que as gentes produzem. As pessoas olham os lugares de maneiras diversas. O mesmo lugar.

\section{Grafias da luz}

Todos os lugares podem ser representados, também, pela fotografia. É evidente que fotografia não é geografia. Fotografia é, tão somente, fotografia. No entanto, a terminologia de ambas as palavras pode ser um bom indicativo de uma possível aproximação: grafia ambas grafias. 
Foto: do grego phos, photos, luz. Grafia: escrita. A "luz escrita" ou a "escrita da luz". Ou o que é captado pela luz. Geografia: a grafia da terra. Luz e terra... A fotografia pode e deve ser um instrumento importante para o fazer geografia na medida em que revela e mostra partes do espaço, dos lugares.

Para muitas pesquisadoras e muitos pesquisadores, como Boris Kossoy, a fotografia pode representar uma importante fonte histórica, ao passo que, se "Toda fotografia é um resíduo do passado" (KOSSOY, 2001, p. 45), pode representar também um resíduo dos lugares, portanto, parte deles.

Em outro momento, o mesmo autor ressaltou:

As imagens fotográficas [...] não se esgotam em si mesmas, pelo contrário, elas são apenas o ponto de partida, a pista para tentarmos desvendar o passado. Elas nos mostram um fragmento selecionado da aparência das coisas, das pessoas, dos fatos, tal como foram (estética/ideologicamente) congeladas num dado momento de sua existência/ocorrência (KOSSOY, 2002, p. 21).

Do tempo para o espaço, ou da História para a Geografia, podemos dizer que as imagens fotográficas podem dar pistas para se tentar desvendar o espaço. Da aparência das coisas, das gentes e dos fatos (congelados? $^{9}$ ), podem apontar elementos que nos revelem as relações entre coisas e gentes.

A partir de uma perspectiva antropológica, Rosane de Andrade acentuou:

se a imagem fotográfica nasce da observação de uma realidade que está contida em uma estrutura cultural, ela vem carregada de signifi-

9 Ver Mauricio Lissovsky, 2008, p. 34: “As fotografias são incertas porque, de modo indecidível, são ícones e índices. Em virtude de sua valência icônica, são capazes de converter pessoas em imagens que, como fantasmas, podem atravessar fronteiras e paredes, e estar presentes em lugares onde seus corpos jamais seriam permitidos [...] As fotografias são instáveis porque, de modo indecidível, são objetos que tomamos agora em nossas mãos e cuja presença nos é absolutamente sincrônica. E, no entanto, carregam consigo os traços da mais irremediável diacronia, daquilo que foi e nunca mais será". 
cados, de fragmentos que deverão ser moldados em um relato único e revelador. A imagem comunga como texto para nos fazer melhor compreender e elaborar uma análise desses significados (ANDRADE, 2002, p. 52).

Quem fotografa o faz observando uma realidade. A imagem é o resultado de um olhar, de uma cultura e de significados. De fragmentos que podem e devem ser inquiridos também por um olho geográfico que, comungando com o texto/contexto, pode "nos fazer melhor compreender e elaborar uma análise" dos significados, para a Geografia, relacionados ao espaço, aos lugares.

Observemos a fotografia (GOETTERT, 2005) a seguir.

Foto 1: Trabalhadores à margem esquerda do rio Purus - Manuel Urbano

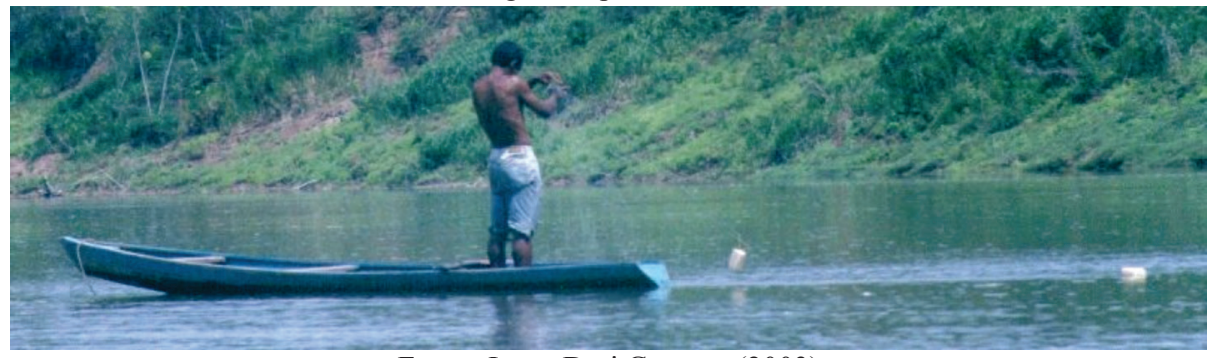

Fonte: Jones Dari Goettert (2003)

A fotografia foi tirada em 2003, no Purus, na cidade de Manuel Urbano. Um homem pesca com a rede. Não sabemos qual o destino dos peixes... Contudo, a imagem possibilita discutir vários aspectos como o trabalho, os trabalhadores, a atividade econômica, os transportes... E é claro, uma discussão que pensasse tais elementos compreendidos em sua dinâmica espacial: onde? Para daí também discutir o quando, o como, o para quem e o porquê.

O uso, a leitura e a análise da fotografia - mas também das imagens em geral - deve ser um estímulo ao fazer geográfico principalmente porque o texto imagético ocupa importante espaço no atual con- 
junto de relações humanas, sejam elas econômicas, políticas, sociais, culturais ou simbólicas. A imagem, contudo, sempre deve ser compreendida como uma produção a partir de certos meios e fins. Não há imparcialidade nas imagens, muito menos nas produzidas pelos meios midiáticas, políticos e até religiosos.

Porque na propaganda de mercadorias e na veiculação de idéias toda imagem se quer sedutora. Eugênio Bucci, em "O olhar mutilado", observou que "O poder, dentro da civilização da imagem, é tanto mais poder quanto mais sabe corresponder e antecipar-se à lógica do desejo”. Nesse sentido, a produção do espetáculo é visto pelo mesmo autor como "um modo de produção" (BUCCI, 2004, p. 231-232).

E seria por isso que:

Não vivemos apenas sob a tirania de relações sociais exclusivamente voltadas à produção e a circulação de mercadorias, não é só isso. Vivemos sob um regime voltado à produção da imagem: da imagem da mercadoria e da imagem como mercadoria. $\mathrm{O}$ culto à mercadoria - que já constituía um fator de barbárie e que apenas se intensificou ao longo século XX - desaguou no culto à imagem da mercadoria, o que permitiu o destravamento do princípio de acumulação e reprodução do capital, lançando ambos a uma escala jamais vista (BUCCI, 2004, p. 231-232).

A mercadoria e a própria produção da imagem são o resultado de um conjunto de relações econômicas e políticas, que tem influência direta nas relações sociais e de como pensamos e fazemos o mundo.

\section{"Ação"}

A arte por excelência que nasce com o capitalismo é o cinema, recheado de imagens. É a própria imagem! No entanto, desprezar completamente a imagem - e aqui o cinema - para o pensar e fazer geografia, pensando e analisando o espaço e seus lugares, seria perder 
de vista que o próprio capitalismo - contraditório e desigual - acaba por possibilitar leituras - imagens e filmes - extremamente críticos em relação à vida e ao espaço das pessoas.

No Acre, por exemplo, inúmeros documentários buscaram apresentar, com os seus jeitos, cortes e recortes os olhares de mulheres e homens em seus lugares, suas vidas, seus trabalhos, suas trajetórias.

O documentário “A verdade em Deus”, produzido em 2003, é um bom exemplo. Com pouquíssimos recursos financeiros, uma professora e um grupo de alunos da Universidade Federal do Acre filmaram e produziram o documentário que mostra a vida de "João Dinizio da Silva, um dos milhares de brasileiros que vivenciam os conflitos pela posse da terra, no Acre e na fronteira entre o Brasil e a Bolívia". ${ }^{10}$

"A verdade em Deus" narra, através da própria fala de João Dionizio e seus amigos e amiga Jurandir, Franciscos e Dona Nazaré, homens e mulher do trabalho, a vida e os lugares de um homem de sessenta e três anos que, nascido em Xapuri, atravessa a fronteira entre Brasil e Bolívia e se embrenha no corte da seringa e outros trabalhas braçais. Depois se desloca para a capital Rio Branco e, ali, vende picolés. Muitos picolés. Para a capital migra atraído pelo Santo Daime. Vira trabalhador urbano. Vira família em bairro periférico da capital. Sem capital.

10 Trecho escrito do documentário “A verdade em Deus". Fundação Elias Mansour; CDIH-UFAC; SETEM/PZ. Produção: Oficina da Imagem. Roteiro de Benedita M. Gomes Esteves, com co-participação de Paulo Roberto N. Ferreira e Ocimar Leitão (2003). Ver também, sobre um importante espaço do centro de Rio Branco, a Praça da Bandeira, o documentário produzido por Nei Ricardo: "Mundo entre as pontes". 


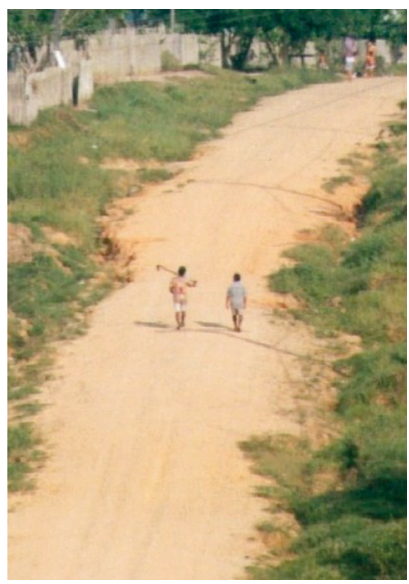

Fotos 2: "A verdade em Deus"

O filme, de aproximadamente meia hora, também possibilita ver ruas, caminhos e estradas da cidade e da floresta. Possibilita ver uma geografia feita de migração, de morte e de vida, de fome e de política, de manejos florestais e de empates, de religiosidade e de memória.

Cada filme é, como este, um conjunto de imagens. Imagens estáticas, mas que, pelo aparelho de "DVD" ou vídeo-cassete, ganham movimento. É a rapidez com que cada imagem passa diante de nós que acaba dando ilusão de movimento:

A imagem que vemos na tela é sempre imóvel. A impressão de movimento nasce do seguinte: "fotografa-se" uma figura em movimento com intervalos de tempo muito curtos entre cada "fotografia" (= fotogramas). São vinte e quatro fotogramas por segundo que, depois, são projetados neste mesmo ritmo. Ocorre que o nosso olho não é muito rápido e a retina guarda a imagem por um tempo maior que 1/24 de segundo. De forma que, quando captamos uma imagem, a imagem anterior ainda está no nosso olho, motivo pelo qual não percebemos a interrupção entre cada imagem, o que nos dá a impressão de movimento contínuo, parecido com a da realidade (BERNARDET, 1981, p. 18-19).

As imagens são cortes e recortes. Os filmes, em sua maioria, são mercadorias. Mas, além disso, como em "A verdade em Deus", podem 
revelar possibilidades de ler o espaço e os lugares, suas continuidades e descontinuidades, os conflitos e as contradições, os amores e as decepções.

Pensando o "papel do filme na sala de aula", especificamente, Jorge Luiz Barbosa foi enfático:

A imagem cinematográfica precisa estar a serviço da investigação e da crítica a respeito da sociedade em que vivemos. Trata-se, portanto, de um movimento de apropriação cognitiva da relação espaço-imagem e, principalmente, da criação de sujeitos produtores de conhecimento e reconhecimento de si mesmos e do mundo (BARBOSA, 1999, p. 112).

Filmes podem ajudar a compreender as relações no espaço. É estourar a pipoca, preparar a sala e depois sonhar. Como no filme "Fitzcaraldo" (de Werner Herzog, 1982), leva-nos a pensar, quase até o seu fim, como eram duros aqueles homens "brancos" usando o povo Ashaninka para as suas travessias... Uma das conclusões que se chega, no entanto, é que o "uso" era também inverso. Ashaninkas usando "brancos"...

\section{Canta o teu canto}

Canto é canto.

Canto do mundo. Música?

Canto do mundo. Aresta?

Pia Vila, Txai Terri e Felipe Jardim compuseram "Rainha da Floresta":

Senhora Rainha da Floresta

Dai-me a força da Ayahuasca

Pra cantar nessas malocas

Pros índios desse lugar

Quero beber caiçuma

E tomar cipó 
Quero bailar o mariri

Nas aldeias do Aquiri

Dai-me a força do jagube

Na luz do lampião

Iluminando todas veredas

Que dão pro meu coração

Como é grande essa floresta

É maior a solidão

Dessa vida passageira

Desse verde sertão

Vou seguindo pela vida

Varejando de ubá

Todos os rios dessa terra

Unidos chegarão ao mar (PIA VILA, 2004).

Junto à voz de Pia Vila, ao som da bateria de Jorge Anzol, das guitarras, violões e teclados de Charles Brown, do contrabaixo de Raildo, da sanfona de Nilton Bararu e da gaita de Neemias Maciel, viajamos para a floresta, pelos lugares da ayahuasca, das malocas indígenas, "pros índios desse lugar". Ali, bebemos caiçuma e tomamos muito cipó, bailamos à luz do lampião... Quantos lugares. Que espaço é esse? Um "verde sertão"?

Talvez, um bando de gentes loucas em um espaço "sertão" mas, "verde" -, mulheres e homens, pela música, pelas batidas, pelo som ecoando nos lugares do "verde sertão", juntam-se a outras tantas e façam, de fato, de cada lugar, um "palco", porque cada palco tem também as suas atrizes e os seus atores.

Gentes de uma música contra-oficial que em lugares loucos vão se fazendo resistência e luta com a única arma que possuem: a música. "Cada palco tem os seus atores" (Banda Duna - no vocal e na guitarra base, Armando; no baixo, Nilton; e, na guitarra solo, Elthon):

Estou achando que tudo tanto faz / e seus pensamentos são tão banais, / passa o tempo mas os dias são iguais, / não há nada no futuro 
e eu não quero voltar atrás / Passam dores pelos corredores, / pensamentos, dissabores, / cada palco tem os seus atores / e eu não lhes devo favores / É preciso se conformar / e não sonhar/ neste lugar / ou então pegar armas / e lutar / Quero saber como manter vivo / o pouco que tem feito o mundo fazer sentido, / a tristeza não bate nem manda aviso, / está sempre comigo, meu mais fiel amigo / Cacos de corações partidos, / pensamentos de sonhos perdidos, / não estamos mortos, estamos feridos, / não nos dão ouvidos / É preciso se conformar / e não sonhar / neste lugar / ou então pegar armas / e lutar (BANDA DUNA, 2005).

No "interior da Amazônia legal", a letra acima participa de lugares e de um movimento também de protesto, de alternativas: "com a finalidade de mostrar o que está rolando na cena alternativa acreana e ajudar as bandas e eventos", "Movimento esse que faz e dá valor à cultura não se acomodando com as mesmices que estão rolando por aí" (BANDA DUNA, 2005).

Sobre a banda, as "[...] influências do Duna são as mais diversas possíveis, mas especialmente do rock inglês e deste, Radiohead, assim como no Brasil, as letras da Legião, é claro. As letras tem o objetivo retratar o universo interior humano, buscando deixar impresso nelas o âmago da experiência vivida. Desta forma, os temas mais comuns são amores, amizades, melancolias, alegrias, solidão, desilusões, esperanças, etc" (BANDA DUNA, 2005).

"Retratar o universo interior humano"! Um lugar? "O âmago da experiência vivida"... No tempo e nos lugares, sem dúvida. Em "cada palco" que "tem os seus atores"... A própria letra é uma metáfora do Acre, de Rio Branco. Do Brasil e do mundo. Ou de partes deles. Uma parte é aqui: "se conformar e não sonhar neste lugar".

Do "universo interior humano", a letra da banda Duna acusa os pensamentos: "são tão banais"; acusa o presente: "não há nada no futuro"; acusa o mundo: "pouco que tem feito o mundo fazer sentido"; 
acusa os sonhos: "perdidos"; acusa a vida: "não estamos mortos"; e acusa a sociedade: "não nos dão ouvidos"... Talvez, para Duna, restaria "pegar armas e lutar".

O poeta espanhol Celaya tem uma frase provocadora para a luta poética: "a poesia é uma arma carregada de futuro"... A banda Duna pega em armas e luta. Luta poeticamente no "interior da Amazônia", em uma música (alter)nativa, paralela... "Periférica", mas resultado do encontro entre vozes do Acre e do mundo: o rock inglês; o Legião, da capital federal...

As duas letras e músicas, "Rainha da Floresta" e "Cada palco tem seus atores", possibilitam pensar o espaço amazônico e alguns lugares da Amazônia. A floresta, em Pia Vila; o lugar onde já não se sonha, em Duna. Que floresta é essa? Quem é, afinal, a floresta? Na floresta as malocas com as gentes índias. E a solidão. No espaço do sonho nenhum, a tristeza, a banalidade, o presente sem futuro, os sonhos perdidos, as dores e os dissabores. Que Amazônia é essa? Grande, muito grande... "É maior a solidão"; e "não nos dão ouvidos".

Música, também insistimos, não é Geografia. Música é música. No entanto, como vimos, a música (suas letras, mas também a música em si, suas notas, melodias, batidas...) pode trazer elementos que despertem questões ligadas ao espaço e seus lugares, na medida em que cada canto é também parte do mundo, vivido e cantado em cada canto. Em cada lugar.

\section{"Jornaleiro"}

Por fim, mas não menos importante, apontamos uma outra possibilidade para a produção do pensar e do fazer uma geografia das gentes no Acre: reportagens jornalísticas, em jornais ou em qualquer outro periódico (principalmente revistas, sejam elas informativas, científicas, ou não). 
Os jornais e revistas (como a literatura em verso ou em prosa, a fotografia, o cinema, a música...) sempre apresentam versões dos fatos, mesmo que o nome do jornal seja "o imparcial". Por isso, na leitura de qualquer um deles, deve-se levar em consideração, quando necessário, a tendência que cada um aponta e, no Acre, principalmente o papel que cada jornal define na relação com governos municipais, estadual e federal (pró ou contra).

No entanto, o jornal, como um relato diário da história, e também da geografia, possibilita navegar por diversos lugares do Acre, lendo pelo jornal os seus lugares e o seu espaço.

De duas edições de um dos jornais da capital Rio Branco, dos dias 28 e 29 de setembro de 2005, ${ }^{11}$ apontamos elementos que ajudem na produção de um pensar e de um fazer geográficos. Em suas manchetes se lê: "Cresce onda de assaltos em Rio Branco", "Vereador médico afirma que é perseguido pela prefeitura", "Deputado quer processar governos de RO e MT por causa da fumaça", "Seringueiros exigem que Funtac paralise exploração no Antimary", "PRF apreende mais de 11 mil itens de contrabando", "Adolescente ateia fogo em casa e família perde tudo", "Prefeito petista de Santa Rosa é acusado de pedofilia e corrupção", "Força-tarefa chega ao Acre e começa hoje o combate a incêndios florestais", "Vice-prefeito de Xapuri é preso por crime ambiental", "Índios continuam a mendigar pelas ruas de Rio Branco", dentro outras. Quantos fatos. Quantos lugares passíveis de leitura.

Um conjunto de indícios poderiam nos levar a pensar aspectos ligados à geografia: o crescimento da violência em Rio Branco (mas onde, especificamente?); a perseguição política e como isso pode evidenciar um rebatimento sócio-espacial; as relações - claras e não-cla-

11 Jornal O Rio Branco, números 8382 e 8383. Rio Branco, Acre 28 e 29/09/2005. 
ras - entre os estados do Acre, de Rondônia e Mato Grosso, possibilitando pensar os modelos de ocupação e uso das três federações; as gentes seringueiras e os projetos de manejos florestais e suas implicações sócio-espaciais; a atividade de contrabando envolvendo o Acre e a Bolívia e a relação com o trabalho informal (mas também formal) nas cidades acreanas; as tensões familiares na constituição e reprodução familiar no centro e nos bairros periféricos; a política e a relação com pedofilia e corrupção e como isso afeta as relações nos lugares; os incêndios florestais: as condicionantes e as problemáticas relacionadas ao espaço; a questão ambiental e as gentes dos lugares; as ruas da capital e a presença de índias e índios pedindo esmolas: as questões que envolvem os territórios e as migrações indígenas, as relações e os contatos entre "brancos" e não-brancos e a formação de um espaço de exclusão, de preconceito e até de discriminação...

Abrindo os jornais e lendo as reportagens, podia-se constatar um espaço feito de conflitos políticos, econômicos, étnicos, familiares... Conflitos que se fazem no interior de um espaço de tensão, exploração, desigualdades e dominação, mas também de resistência. Quando um grupo de famílias seringueiras se organiza e reivindica melhores condições de vida - trabalho, transporte, educação, saúde... - na floresta, o faz na cidade. A luta transcende o lugar de vida, da moradia e irrompe o lugar política constituindo, pela organização, um movimento de resistência frente às dificuldades de sobrevivência na floresta:

Um grupo de seringueiros do projeto de manejo do Antimary, além de moradores do ramal Espinhara, que dá acesso ao local, no município de Bujari (25 km de Rio Branco), esteve ontem na sede da Fundação de Tecnologia do Acre (Funtac) para exigir a imediata paralisação do projeto. [...] No Antimary, conta [Osmarino Amâncio, "líder rural"], as coisas estão sendo feitas sem controle, sem o menor critério. Informa que até mesmo árvores com menos de trinta centímetros de diâmetro estão sendo cortadas. Isso sem falar no fato de que árvores que estão fora da estrada de seringa também são 
cortadas e não são pagas aos seringueiros. [...] no projeto não se investe em manejo verdadeiro, já que na sua avaliação o que acontece é somente a retirada (sem controle) da madeira. "Deveria ter aqui investimentos para que essa madeira fosse beneficiada e agregar valores, mas ao contrário, se instituiu a depredação", comentou. ${ }^{12}$

A atuação do Estado e de empresários do ramo madeireiro é questionada. A problemática articula trabalhadoras e trabalhadores que pensam e fazem a resistência contra a explotação-exploração e mercantilização desenfreada da natureza. Ganhos políticos e econômicos para uns e dificuldades de sobrevivência para as mulheres e homens da floresta. Na Funtac, lugar do Estado, o encontro/confronto entre homens do governo e mulheres e homens do trabalho. O local, aparentemente neutro, vai se revelando, pela fala da denúncia e da reivindicação, em lugar de resistência.

Mulheres e homens da floresta resistem e falam na cidade. Famílias seringueiras. Mas, outras mulheres e outros homens (principalmente as primeiras com filhas e filhos pequenos na mão e no chão), também da floresta, mostram-se em ruas do centro de Rio Branco, re-existindo no olhar muitas vezes recriminador das mulheres e homens urbanos. Mulheres e crianças índias "continuam mendigando na Capital":

Mesmo depois das operações desenvolvidas pela Fundação Nacional do Índio (Funai), dezenas de índios continuam mendigando no Centro [de Rio Branco]. Além de ficarem expostos ao choque cultural e à violência urbana, os índios, a maioria mulheres, usam suas crianças na mendicância. ${ }^{13}$

No centro de Rio Branco o urbano vira floresta. Na Floresta Estadual do Antimary a floresta vira negócio... Aparentemente reportagens distantes e díspares, ambas revelam um espaço carregado de tensões, conflitos e contradições. Nele, mulheres e homens da floresta 12 Idem, $\mathrm{n}^{\circ} 8382$, p. 8.

13 Idem, no 8383 , p. 4. 
ocupam a cidade para melhorar a vida lá, na floresta; também nele, no espaço urbano, outras mulheres, com suas crianças, pedem dinheiro, pouco dinheiro, porque também a floresta, nos territórios indígenas, é prenhe de tensões, de dificuldades e de contradições. Todas e todos, contudo, parecem resistir a todos e a tudo.

\section{$\operatorname{Espaço~(em/en)cena~}$}

Resistir para re-existir: no espaço, em seus lugares, as gentes se fazem na expressão concreta de seus pensares, em seus fazeres, produzindo e reproduzindo espaço. Lugares de desejo, às vezes. Lugares de tensão, em outras.

Metaforicamente, um palco. Para o teatro, se quisermos... Um "espetáculo" que pode ajudar na compreensão das relações no espaço, nos lugares. Com as gentes em cena, encenando a vida.

De um bonito depoimento da escritora - e atriz - Francis Mary, trazendo momentos sobre a montagem do espetáculo "Grilagem na cabeça" (uma das peças-relâmpago do teatro "Baixo da Égua", do grupo Testa, montado em 1979), vem o fechamento deste texto. Porque, no espetáculo, Francis Mary foi narrando momentos dele - do real à cena - e, talvez mesmo sem querer, mostra-nos o movimento no espaço em que as gentes - "atrizes" e "atores" - pensam, se fazem e se mostram para outras gentes, mas que não "assistem" passivamente: o espaço e seus lugares, que também se fazem pela literatura, fotografia, cinema, música e teatro, dentre outros jeitos de apresentar e de representar, são mais do que aquilo que é escrito, mostrado, falado ou cantado; são, sobretudo, aquilo que as "espectadoras" e os "espectadores" lêem, vêem, ouvem, repetem assobiando ou rejeitam murmurando...

os jornais noticiavam que, em Boca do Acre, colonos invadiam terras indígenas gerando um conflito que poderia causar mortes. Lideranças seringueiras e indígenas se mobilizavam, preocupadas com $o$ desfecho dos acontecimentos. Nas ONGs, nos sindicatos, nas mesas 
de bares o assunto era motivo de conversas, principalmente porque não era uma luta entre um fazendeiro e um grupo de índios ou colonos, mas uma briga dos povos da floresta entre si. [...] O espetáculo começa assim. Na platéia, índios de um lado e colonos do outro. No palco o dilema sendo encenado com muito humor: um grileiro com um cabeção branco enorme grilando as terras dos índios para vender a colonos, um ator representando a FUNAI e outro, o INCRA. Claro que não podíamos apresentar a solução para o conflito, pois nada tinha sido resolvido. Então, na cena final, os atores ficavam "congelados" e pedíamos ao público que usasse os corpos como uma massa de modelar para apresentar soluções. Era um barato: uns tiravam a faixa da FUNAI e a colocavam num índio; outros, a faixa do INCRA num colono. Alguns juntavam índios e colonos, colocavam armas em suas mãos e matavam o grileiro e outras cenas que não me lembro... (MARQUES, 2005, p. 165-167).

Agora deite na rede atada no jardim ou na calma do quintal, "viaje" com a "Rainha da floresta" na voz de Pia Vila... E depois levante, pinte a tua faixa e coloque em alguém. A cor da faixa, o tamanho e as palavras é de tua escolha. A escolha dos lugares e das gentes companheiras, também é tua... E a depender das voltas e curvas e barrancos dos rios, todas e todos "unidos chegarão ao mar!"

\section{POETRY, IMAGES AND SPEECHES: SUNG, SHOWN, AND SPOKEN PEOPLE (POSSIBILITIES TO READING PEOPLE AND PLACES IN MARGINS AND BOUNDARIES OF GEOGRAPHY)}

\section{ABSTRACT}

This article is aimed to think about the people, borders and places of Acre Amazon, from incursion on literary and imagistic representations, highlighting meandering rivers, forests and cities, in the way of weaving a kind of "geographical translation" that, assuming the freedom of the literary text, can penetrate and occupy places in less rigid cracks than those allowed by science, especially if one consider that its narrative may be closer to the communities of readers. The identity construction/invention of a certain acreanidade (as the quality of belonging to Acre) is scrutinized in the interpretation of texts and images, punctuating an analysis that is also concerned with the power relations established there, i.e., an analysis that meddles amid contradictions, ambiguities, contrasts, tensions and 
conflicts that materialize themselves in the production of the space, as well as in the narrative and theforms of idealization of that space.

KEYWORDS: Acre Amazon. Geography. Literature. Poetry. Borders.

\section{REFERÊNCIAS}

ANDRADE, R.. Fotografia e Antropologia: olhares fora-dentro. São Paulo: Estação Liberdade; EDUC, 2002.

BANDA DUNA. Coice Core Zine - Gritos ensurdecidos (coletânea). CD. Rio Branco, 2005.

BARBOSA, J. L. Geografia e cinema: em busca de aproximações e do inesperado. In: CARLOS, A. F. A. (org.). A geografia na sala de aula. São Paulo: Contexto, 1999, pp. 109-133.

BERNARDET, J.C. O que é cinema. $3^{\mathrm{a}}$ ed. São Paulo: Brasiliense, 1981. BUCCI, E. O olhar mutilado. In: NOVAES, A. (org.). Civilização e barbárie. São Paulo: Companhia das Letras, 2004, pp. 227-245.

ESTEVES, B. M. G. "A verdade em Deus". Fundação Elias Mansour; CDIH-UFAC; SETEM/PZ. Produção: Oficina da Imagem. Roteiro de Benedita M. Gomes Esteves, com co-participação de Paulo Roberto N. Ferreira e Ocimar Leitão (2003).

ESTEVES, F. Enredos da memória. $2^{a}$ ed. Rio Branco: Fundação Elias Mansour, 2002.

LOPES, M. E. P. S. Motivos de mulheres na ignota floresta amazônica: produção de escritoras acreanas das décadas de oitenta a noventa. Tese de Doutorado. Salvador: Programa de Pós-Graduação em Letras e Linguística-UFBA, 2005.

FERRANTE, M. J. Seringal. 2a ed. Rio Branco: UFAC-Fundape, 2003. GOETTERT, J. D. "Só o dono pode ter roçado": considerações iniciais sobre uma Geografia em Terra Caída, de José Potyguara. In: Revista Uáquiri. N. 1. Rio Branco; Departamento de Geografia - UFAC, 2003, pp. 101-120.

GOETtERT, J. D. Do olho do umbigo do Mapinguari. Rio Branco: 
EdUFAC, 2005.

GOETTERT, J. D. Lugares, jeitos e sujeitos: cortes e recortes da BR-364 acreana. Rio Branco: EdUFAC, 2005.

GOETTERT, J. D. O espaço e o vento: olhares da migração gaúcha para Mato Grosso de quem partiu e de quem ficou. Tese de Doutorado. Presidente Prudente: Programa de Pós-Graduação em Geografia - FCT UNESP, 2004.

GOETTERT, J. D. Um encontro com Maria (escalas da fome). In: Revista Uáquiri. N. 2. Rio Branco: Departamento de Geografia - UFAC, 2004, pp. 146-158.

GONÇALVES, C. W. P. Geografando nos varadouros do mundo: da territorialidade seringalista (o seringal) à territorialidade seringueira (a Reserva Extrativista). Brasília: IBAMA, 2003.

HAESBAERT, R.. Territórios alternativos. Niterói: EdUFF; São Paulo: Contexto, 2002.

KOSSOY, B. Fotografia \& História. $2^{\text {a }}$ ed. São Paulo: Ateliê Editorial, 2001.

KOSSOY, B. Realidades e ficções na trama fotográfica. $3^{\text {a }}$ ed. São Paulo: Ateliê Editorial, 2002.

LIMA, F. M. A. Pré-históricas e outros livros. Rio Branco: Fundação Cultural Elias Mansour, 2004.

LIMA, S. T. Percepção ambiental e Literatura: espaço e lugar no Grande sertão: veredas. In: DEL RIO, V., OLIVEIRA, L. (Orgs.). Percepção ambiental: a experiência brasileira. 2 ed. São Paulo: Studio Nobel, 1999, pp. 153-172.

LISSOVSKY, M. O que fazem as fotografias quando não estamos olhando para elas? In: BARRENECHEA, M. A. (Org.). Dobras da memória. Rio de Janeiro: 7 Letras, 2008, pp. 26-36.

MAIA, M. Rios e barrancos do Acre. $2^{\text {a }}$ ed. Niterói, 1978.

MARQUES, M. P. S. C. M. A cidade encena a floresta. Rio Branco: 
EdUFAC, 2005.

MONTEIRO, C. A sinuca da olaria. Rio Branco: Printac, 2003.

OLIVEIRA, L. A. P. O sertanejo, o brabo e o posseiro: a periferia de Rio Branco e os cem anos de andança da população acreana. Dissertação de Mestrado. Belo Horizonte: Dentro de Desenvolvimento e Planejamento Regional - UFMG, 1982.

PIA VILA. Aldeia Sideral. CD. Rio Branco: Fundação Elias Mansour, 2004.

POMPERMAIER, A. Pétalas nas veias. Rio Branco: Fundação Elias Mansour, 2003.

POTYGUARA, J. Terra caída. Rio Branco. Fundação Cultural do Estado do Acre, 1998.

SILVA, L. R. Acre: prosa \& poesia: 1900-1990. Rio Branco: UFAC, 1998. 